\title{
The effect of the carbodiimide cross-linker on the structural and biocompatibility properties of collagen-chondroitin sulfate electrospun mat
}

This article was published in the following Dove Press journal: International Journal of Nanomedicine

\author{
Sheyda Akhshabi' \\ Esmaeil Biazar ${ }^{2}$ \\ Vivek Singh ${ }^{3}$ \\ Saeed Heidari Keshel ${ }^{4}$ \\ Nagaraja Geetha' \\ 'Department of Studies in \\ Biotechnology, University of Mysore, \\ Manasagangotri, Mysuru, Karnataka, \\ India; ${ }^{2}$ Department of Biomaterials \\ Engineering, Tonekabon Branch, \\ Islamic Azad University, Tonekabon, \\ Iran; ${ }^{3}$ Prof Brien Holden Eye Research \\ Center, Sudhakar and Sreekanth \\ Ravi Stem Cell Biology Laboratory, \\ L.V. Prasad Eye Institute, Hyderabad, \\ Telangana, India; ${ }^{4}$ Department of \\ Tissue Engineering and Applied \\ Cell Sciences, School of Advanced \\ Technologies in Medicine, Shahid \\ Beheshti University of Medical \\ Sciences, Tehran, Iran
}

Background: Collagen and chondroitin sulfate (CS) are an essential component of the natural extracellular matrix (ECM) of most tissues. They provide the mechanical stability to cone the compressive forces in ECM. In tissue engineering, electrospun nanofibrous scaffolds prepared by electrospinning technique have emerged as a suitable candidate to imitate natural ECM functions. Cross-linking with 1-ethyl-3-(3-dimethyl-aminopropyl)-1-carbodiimide hydrochloride/ $\mathrm{N}$-hydroxy succinimide can overcome the weak mechanical integrity of the engineered scaffolds in addition to the increased degradation stability under physiological conditions.

Materials and methods: This study has synthesized nanofibrous collagen-CS scaffolds by using the electrospinning method.

Results: The results have shown that incorporation of CS in higher concentration, along with 1-ethyl-3-(3-dimethyl-aminopropyl)-1-carbodiimide hydrochloride/ $N$-hydroxy succinimide, enhanced mechanical stability. Scaffolds showed more resistance to collagenase digestion. Fabricated scaffolds showed biocompatibility in corneal epithelial cell attachment.

Conclusion: These results demonstrate that cross-linked electrospun CO-CS mats exhibited a uniform nanofibrous and porous structure, especially for lower concentration of the cross-linker and may be utilized as an alternative effective substrate in tissue engineering.

Keywords: collagen, chondroitin sulfate, CS, extracellular matrix, ECM, cross linker, electrospinning, nanofiber

\section{Introduction}

It is well-known that all anchorage-dependent cells in tissues reside in the extracellular matrix (ECM) with the capability of providing the structural and mechanical support. They support the residing cells attachment and proliferation as well as conducting cell bioactivities and tissue developmental dynamic processing by providing proper growth factors and well-timed degradation required for neovascularization. ${ }^{1}$ ECM is composed of a variety of fibrous proteins and glycosaminoglycans (GAGs) (which are unbranched polysaccharide chains covalently attached to the protein cores). GAGs, which are negatively-charged molecules, possess sulfate and carbonyl groups on their repeated sugar units. These units can absorb a large amount of water molecules and create a gel-like substrate embedded in the fibrous proteins. This property provides a swelling pressure which contributes in compressive stress resistances. ${ }^{2}$ Therefore, the design and the construction of alternative substrates, along with the potential of presentation, which are partially close to the native ECM susceptibility, have become one of the major challenges for researchers in the field of tissue engineering and regenerative medicine. Due to the fibrous form of organization in most tissues,
Correspondence: Nagaraja Geetha Department of Studies in Biotechnology, University of Mysore, Manasagangotri, Mysuru 570 006, Karnataka, India Tel +9l 821 24l 9462

Email geetha@appbot.uni-mysore.ac.in 
as well as natural ECM proteins, nanofiber-based scaffolds have been engineered rapidly as suitable candidates to provide cell and tissue physical scaffoldings. ${ }^{3,4}$ Among many existing techniques for fabrication of nanofibers, such as self-assembly, phase separation, melt blowing, flash-spinning, etc., the method electrospinning (described in detail elsewhere ${ }^{5}$ ) has emerged as a widely used in terms of constructing fibers with the possible ability to control fiber diameter. The controlled fiber diameter generated through electrospinning varies from $100 \mathrm{~nm}$ to several microns. It can produce the ultra fine fibers with special orientation, high surface-to-volume ratio, surface morphology, pore geometry, and three-dimensional architecture. ${ }^{6-18}$ Thus, the choice of electrospinning technique takes into account the properties of the selected biomaterial, for instance, utilization of natural ECM proteins, to achieve a well-designed nanofiber scaffold, which imitates the desired natural ECM. It is obvious that collagen (CO) is the main abundant ECM protein, and it provides flexibility and structural strength to the ECM tissues. ${ }^{19-23}$ For this reason, CO-based scaffolds have been widely used as the most appropriate component for engineered scaffolds. In addition, the utilization of marine-based COs for the sake of sole intrinsic properties, such as biocompatibility and biodegradability, has attracted more importance. ${ }^{24-26}$ One of the major challenges faced with engineered scaffolds is the insufficient mechanical stability under various physiological conditions causing out of time degradation and collapse of scaffolds prior to tissue formation along with remodeling. Researchers are inspired by the efficacious factor in the creation of natural ECM stability, trying to overcome the aforementioned problems and the improvement of the scaffold resistance. As mentioned above, $\mathrm{CO}$ and other fibrous proteins are embedded in the hydrated GAGs mesh and get proper resistance through covalently binding to ECM proteins. ${ }^{27,28}$ In this case, the incorporation of GAG molecules to the engineered scaffolds has become promising. Recent attention has been focused on chondroitin sulfate (CS), which is a negatively sulfated GAG, and is a major structural component of most of the ECM, such as cartilage, bone, and cornea. ${ }^{29}$ It is suggested that CS should be involved with important cellular processes like receptor binding, cell adhesions, cell growth, and migrations. ${ }^{30}$ Scaffolds containing CS have been widely applied for various goals, especially regeneration of skin, ${ }^{31}$ articular cartilage, ${ }^{32}$ conjunctiva, ${ }^{33,34}$ nerve, ${ }^{35}$ and bone. ${ }^{36,37}$ Since CO fibrils are strengthened through covalent cross-linking between lysine residues in native ECM, the creation of a network by cross-linking between nanofibers with cross-linkers can be another option to cope with mechanical stability of engineered scaffolds. ${ }^{38}$ Among chemical cross-linking agents, 1-ethyl-3-(3-dimethyl-aminopropyl)-1-carbodiimide hydrochloride (EDC) is a relatively low cytotoxic compound compared to glutaraldehyde, which facilitates the formation of amide bonds between carboxylic and amino groups on the CO molecules, either alone or with $N$-hydroxy succinimide (NHS). EDC has been widely used to cross-link reconstituted $\mathrm{CO}$ fibrils, helping to prevent the formation of side products; moreover, it increases the reaction rate. ${ }^{39-41}$ The goal of the present study is to fabricate a nanofibrous CO-CS scaffold with different blend ratios of CS along with two woven and aligned morphologies. The mixture of hexafluroisopropanol (HFIP) and water was used as the solvent to dissolve the blended $\mathrm{CO}$ and $\mathrm{CS}$ to obtain a homogeneous solution with a suitable viscosity for electrospinning experiments. Fabricated nanofibrous scaffolds were cross-linked with two concentrations of EDC/NHS cross-linker. The in vitro cytocompatibility assays for scaffolds were performed by using human corneal epithelial (HCE) cells.

\section{Materials and methods Scaffold preparation}

Fish type I CO was prepared by following the standardized protocol. ${ }^{42}$ Chondroitin-6-sulfate (CS-6) sodium salt from shark cartilage, EDC, NHS, MES (SIGMA), 3-(4,5-dimethylazol-2-yl)-2,5-diphenyl-2H-tetrazolium bromide (MTT), and type I collagenase from Clostridium histolyticum were purchased from Sigma-Aldrich Co. (St Louis, MO, USA). Initially, $\mathrm{CO}$ was dissolved at a determined concentration in HFIP (1,1,1,3,3,3-Hexafluoro-2-propanol) solvent $(10 \%$ $\mathrm{W} / \mathrm{V})$, and then, it was mixed at a concentration of CS solution $(10 \% \mathrm{~W} / \mathrm{V})$. Next, the resulting suspensions were filtered to remove any impurities. After that, the spinning solutions were transferred into a 5-mL glass syringe fitted with a 7-mm needle, which was attached to a syringe pump of electrospinning apparatus (Nano Fiber Electrospinning Unit; Holmarc Opto-Mechatronics Pvt Ltd., Kerala, India). The needle-tocollectors distances were fixed at $12 \mathrm{~cm}$. A similar $10 \mathrm{KV}$ voltage was applied to the needle of the syringe for both woven and aligned morphologies. Later, an electric field was generated between the spinning solution and the collectors. A grounded plate and rotating collector were utilized for collecting woven and aligned fibers with the rotating speed of 100 and 3,000 rpm, respectively, that was covered with aluminum foil. CO-CS nanofibers are formed by the electrically charged jet movement with the flow rate of $0.8 \mathrm{~mL} / \mathrm{h}$ toward the collectors, once the charge overcomes the surface tension of electrospinning solutions and subsequent evaporation of the solvent. Finally, nanofibrous mats were carefully detached 
from the collector and dried in vacuum for 2 days at room temperature to remove solvent molecules completely.

\section{Cross-linking of scaffolds}

In order to extend the stability of the electrospun mats in physiological conditions, all electrospun CO-CS mats were cross-linked with the EDC carbodiimide in the presence of NHS at two concentrations, ie, 200 and $600 \mathrm{mM}$ with the ratio-EDC/NHS=2:1 W/W. The reaction mechanism is presented in Figure 1. Cross-linking of $\mathrm{CO}-\mathrm{CS}$ mats was carried out by soaking the scaffolds in 200 and $600 \mathrm{mM}$ of EDC/NHS solutions in an acetone/water mixture $\left(\mathrm{V}_{\text {ethanol }} / \mathrm{V}_{\mathrm{H} 2 \mathrm{O}}=90 / 10\right)$ and incubated through shaking for $4 \mathrm{~h}$, respectively. Later, cross-linked mats were rinsed in deionized water to remove the residual cross-linking solution and put in an oven at $30^{\circ} \mathrm{C}$ for $24 \mathrm{~h}$. The surface characteristics of modified fibers were studied by scanning electron microscopy (SEM, Hitachi $\mathrm{S}-3000 \mathrm{~N}$ ) to analyze the changes in the surface morphology. Attenuated total reflectance-Fourier transform infrared spectroscopy (ATR-FTIR) studies were carried out for mats of electrospun before and after cross-linking using ATR-FTIR (Spectrum Two, Perkin Elmer Inc., Waltham, MA, USA). The tensile strength (stress-strain analysis) of CO-CS nanofibrous mats (thickness $=0.04 \mathrm{~mm}$, width $=14 \mathrm{~mm}$ ) was measured using a universal testing machine (Dak System Inc. U.T.M. 7200, India) under an extension rate of $1 \mathrm{~mm} / \mathrm{min}$ and $100 \mathrm{~N}$ load cell. All data are given as mean and SEM unless noted. One-way analysis of variance with post hoc Tukey mean comparison tests and unpaired Student's $t$-tests were conducted at a significant level of $P<0.05$. A minimum of three replicate samples were used for all experiments.

\section{Degradation of nanofibrous mats}

In vitro enzymatic degradation tests were carried out on the cross-linked and non-cross-linked scaffolds by using bacterial collagenase (from C. histolyticum; Sigma-Aldrich Co.) to degrade the $\mathrm{CO}$ and CS-6 components, respectively. The concentrations were determined experimentally by observing the extent of degradation in samples of matrix after 2, 8, and 24 $\mathrm{h}$ at $37^{\circ} \mathrm{C}$ using enzymes. CO-CS scaffolds were accurately weighed and placed in $1 \mathrm{~mL} 0.1 \mathrm{M}$ Tris- $\mathrm{HCl}(\mathrm{pH}$ 7.4) containing $125 \mathrm{CDU} / \mathrm{mg}$ (CO digestion units $/ \mathrm{mg}$ ) bacterial collagenase and incubated for the mentioned time intervals. At the end of each incubation time, samples were removed and washed threefold in distilled water and finally lyophilized. Scaffold biodegradability was determined from the weight of residual scaffold and expressed as a percentage of the original weight $t^{43,44}$ and SEM morphology after different immersion time periods.

\section{Cellular analyses}

The cytocompatibility assay of the electrospun scaffolds was carried out by using a Human corneal epithelial cell line (HCE-P3) from the Stem Cell Biology Laboratory, Prof Brien Holden Eye Research Center, L. V. Prasad Eye Institute, Hyderabad, India (the HCE cell line was a kind gift from Dr Araki-Sasaki K, Osaka University, Medical School, Osaka, Japan, to Professor Brien Holden Eye Research Center, L. V. Prasad Eye Institute, Hyderabad, India). ${ }^{45}$ Scaffolds were selected for the study, based on the characterization results, and the scaffolds showing better properties were chosen for cell culture studies. The scaffolds were cut into a round shape of $\sim 22 \mathrm{~mm}$ in diameter each, prior to cell seeding, and were sterilized by placing in $75 \%$ ethanol for $10 \mathrm{~min}$. Later, the scaffolds were peeled off gently from the support substrate and spread without folds over the round-shaped cover slip. The samples were further placed in 12-well culture plates, air-dried inside a biosafety hood. The samples were further placed in 12-well culture plates, air-dried inside a biosafety hood. Human amniotic membrane (HAM) was obtained from the Ramayamma International eye bank (RIEB), L. V. Prasad

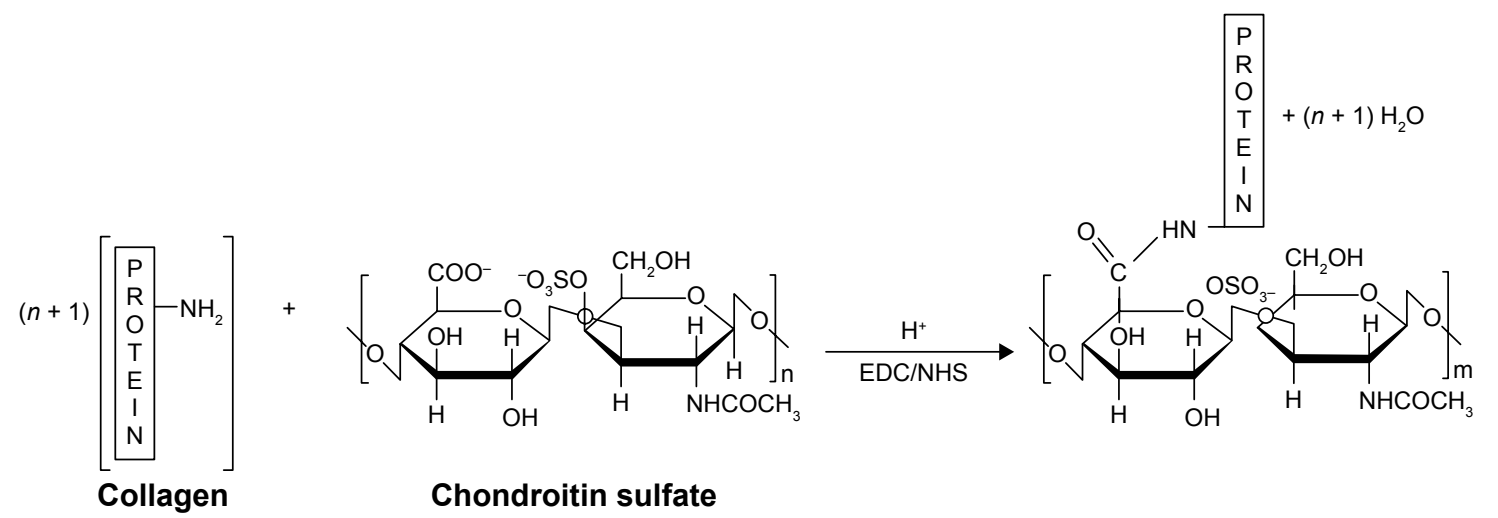

Figure I Schematic illustration of the reaction mechanism of CO and CS with EDC/NHS cross-linker.

Abbreviations: CO, collagen; CS, chondroitin sulfate; EDC, I-ethyl-3-(3-dimethyl-aminopropyl)-I-carbodiimide hydrochloride; NHS, N-hydroxy succinimide. 
Eye Institute, Hyderabad, India, with approval from the institutional ethics committee (LVPEI-IC-SCR 04-15-008, this IRB was for the use of amniotic membrane when studying in vitro using the above cells) and used as a control. The amniotic membrane was prepared from the placenta, removed under sterile conditions. RIEB collects placenta discarded during Caesarean operations only. This membrane is then cleaned and treated. The amniotic membrane pieces processed by the RIEB are being made available for surgeons in the Institute for Ocular Surface Surgery and Reconstruction and for use in research (http://eyebank.lvpei.org/productdevelopment.php). The amniotic membrane was processed by washing with $2 \times$ PBS (DPBS powder, D5652- 10X1L, Sigma-Aldrich Co.) containing streptomycin and penicillin (S9137-25G, P3032-10MU; Sigma-Aldrich Co.) under sterile conditions and gently removed from the nitrocellulose membrane with the epithelial side surface upward. Excess glycerol was removed by washing the membrane with $1 \times$ PBS (DPBS powder, D5652-10X1L, Sigma-Aldrich Co.), and the surface epithelium layer was removed by incubating the membrane with $0.25 \%$ trypsin solution (T4799-10G, Sigma-Aldrich Co.) for $30 \mathrm{~min}$ at $37^{\circ} \mathrm{C}$, and the digested epithelium layer was gently removed using a cell scraper (3010, Corning, NY, USA). The membrane was washed with $1 \times$ PBS to discard the spent and finally mounted uniformly without folds over a roundshaped cover slip. ${ }^{43} 0.1 \times 10^{6} \mathrm{HCE}$ cells were taken in $100 \mu \mathrm{L}$ of DMED/F12 (D0547-10X1L, Sigma-Aldrich Co.) with 10\% FBS (Gibco, CA, USA), 10 ng/mL human recombinant Epidermal Growth Factor (E9644, Sigma-Aldrich Co.), 5 g/ mL human recombinant Insulin (I2643, Sigma-Aldrich Co.), $100 \mathrm{U} / \mathrm{mL}$ penicillin (P3032-10MU, Sigma-Aldrich Co.), and $100 \mu \mathrm{g} / \mathrm{mL}$ streptomycin (S9137-25G, Sigma-Aldrich Co.) was seeded over both scaffolds and amniotic membrane (AM) followed by incubation for $1 \mathrm{~h}$ to permit the cells to attach on the surface of the scaffolds. The freshly prepared same medium was added $2 \mathrm{~mL}$ to each sample, incubated for up to 7 days, and similarly repeated every 3 days. The proliferation and cell viability analyses were checked after $72 \mathrm{~h}$ of HCE, post-culturing with 3-[4,5-dimethylthiazol-2-yl]diphenyltetrazoliumbromide (MTT), to which $20 \mu \mathrm{L}$ of MTT substrate $(2.5 \mathrm{mg} / \mathrm{mL}$ stock solution prepared in phosphate buffered saline [PBS], Sigma Aldrich Co.) was added to each well, and the plates were incubated for an additional $4 \mathrm{~h}$. Later, the medium was removed, and the cells were solubilized in $100 \mu \mathrm{L}$ of dimethyl sulfoxide (DMSO) to dissolve formazan crystals, and colorimetric analysis was performed at $570 \mathrm{~nm}$ (RAYTO, micropleat reader). To carry out the SEM studies, the medium was removed from the cultured scaffolds and HAM and washed with phosphate buffer (PB). Fixation of the samples was done by immersing in $2.5 \%$ glutaraldehyde buffered with $0.1 \mathrm{M} \mathrm{PB}$ and stored for $4 \mathrm{~h}$ at $4^{\circ} \mathrm{C}$. Samples were later washed with $\mathrm{PB}(3 \times 10 \mathrm{~min})$ and dehydrated in ascending serial concentration of ethanol $(20 \%$ $[5 \mathrm{~min}] \rightarrow 40 \%$ [5 min $] \rightarrow 60 \%$ [5 min $] \rightarrow 80 \%$ [5 min $] \rightarrow 100 \%$ [30 s] $),{ }^{14}$ and finally, the samples were dried in a desiccator and sputter-coated with gold and imaged with SEM.

\section{Results Morphological characterization}

Electrospinning is a fiber production method, which uses the fabrication of woven and aligned morphologies of $\mathrm{CO}$ and CO-CS fibers using HFIP solvent. Figure 2 shows the SEM images of the non-cross-linked electrospun mats at different morphologies. The smooth and homologous bead-free nanofibers have been shown clearly in these figures. The average sizes for the woven and aligned $\mathrm{CO}$ nanofibers were about 400 and $500 \mathrm{~nm}$, and for CO-CS blends were about 300 and $400 \mathrm{~nm}$. The electrospun collagenous scaffolds indicate insufficient resistances to withstand dissolution upon exposure to any aqueous solution and mechanical integrity, due to the lack of native inter and intra-cross-linker in fabricating mats. It is rendered as a notable shortcoming related to electrospun mats, which can be eliminated by cross-linking. ${ }^{47,48}$ The EDC (hetero-bifunctional water-soluble carbodiimide) as a zero length (ie, without its incorporation into macromolecule) cross-linker agent has been utilized widely among chemical cross-linkers. SEM images of the cross-linked nanofibrous mats at different concentrations are shown in Figure 3. After cross-linking at different concentrations, the average sizes of nanofibers were bigger than non-cross-linked samples. The CO and $\mathrm{CO}-\mathrm{CS}$ blend samples cross-linked in EDC solution with higher concentrations $(600 \mathrm{mM})$ have shown disordered morphologies and dimensional gelation without unsuitable porosity as a scaffold for cellular growth and, in turn, prevent cell penetration following the increase in the extent of cross-linking (Figure 3B, D, F, and H). This may be due to the greater ratio of EDC (600 mM) to proteins, which caused more reaction in electrospun nanofiber mats, whereas the samples cross-linked at lower concentrations ( $200 \mathrm{mM}$ ) maintained morphology with high porosity and open pores (Figure 3A, C, E, and G).

\section{ATR-FTIR analysis}

The representative FTIR absorption spectra of the noncross-linked and cross-linked electrospun mats are shown in Figure 4. The IR peaks of the amide I, II, and III bands 

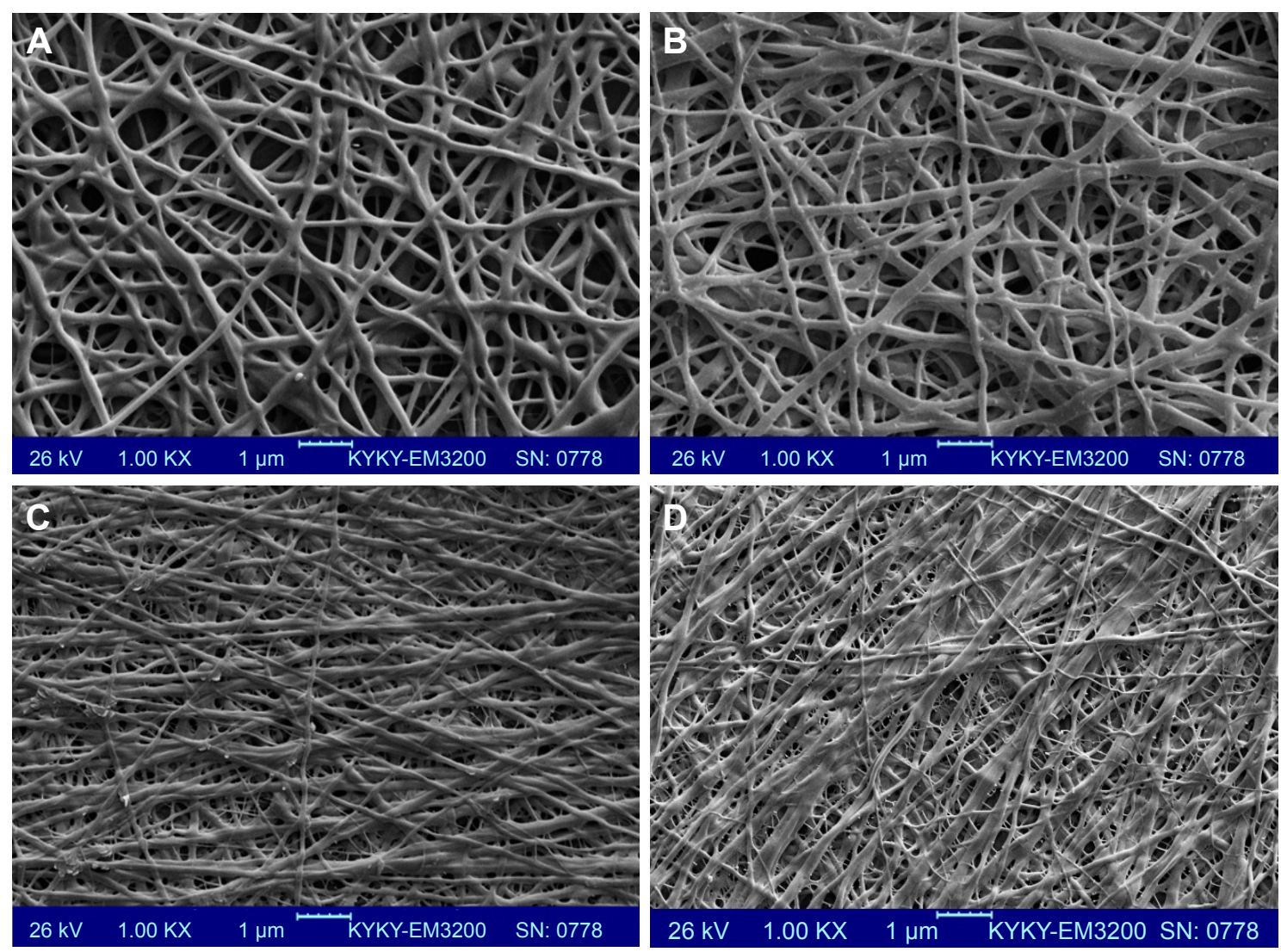

Figure 2 SEM images of the non-cross-linked woven (A) CO and (B) CO-CS; I,000×, and the aligned mats (C) CO and (D) CO-CS; I,000x.

Abbreviations: SEM, scanning electron microscopy; $\mathrm{CO}$, collagen; $\mathrm{CS}$, chondroitin sulfate.

related to type I collagen are presented at 1,660, 1,548, and $1,239 \mathrm{~cm}^{-1}$, respectively. The bands at 3,450 and $2,850 \mathrm{~cm}^{-1}$ were observed, and they represented the stretching of $-\mathrm{OH}$, and $-\mathrm{CH} 3$, respectively. The $\mathrm{C}=\mathrm{O}$ and $\mathrm{C}-\mathrm{O}$ stretching vibration of ionized carboxyl group was observed at 1,377 and $1,416 \mathrm{~cm}^{-1}$ bands, whereas the bands at 1,066 and $1,127 \mathrm{~cm}^{-1}$ represent $\mathrm{C}-\mathrm{O}$ stretching vibration of hydroxyl groups. The $\mathrm{S}=\mathrm{O}$ stretching vibration located at about $1,239 \mathrm{~cm}^{-1}$ is related to the presence of CS. Also, the reaction between amino and carboxylic groups of $\mathrm{CO}$ amino acids, ie, lysine residues, formed the amide linkage $(\mathrm{CONH})$ with strong peaks that took place during the cross-linking process. The amide and sulfonamide linkages are formed under acidic conditions due to the reaction of the EDC cross-linker with hydroxyl groups of sulfate and carboxyl groups of CS. The $\mathrm{C}-\mathrm{N}$ peak intensity at $1,404 \mathrm{~cm}^{-1}$ of EDC-cross-linked samples was higher than non-cross-linked samples, which might indicate that the EDC-cross-linked samples contained a higher amount of amide bonds due to the EDC cross-linking. In addition, $\mathrm{CO}$ and CS samples exhibit similar peaks; however, their amide bands were slightly increased. The other $\mathrm{CO}-\mathrm{CS}$ samples also exhibited a broadened $\mathrm{C}-\mathrm{O}$ stretching zone.
In vitro degradation stability of the non-cross-linked and cross-linked mats was evaluated in the presence of the collagenase for all electrospun $\mathrm{CO}$ and $\mathrm{CO}-\mathrm{CS}$ mats. Enzymatic degradation has been studied by monitoring the weight loss of samples after 4, 24, and $72 \mathrm{~h}$ of incubation. Non-cross-linked mats have shown $>95 \%$ loss in mass after $4 \mathrm{~h}$ of in vitro degradation in the collagenase (Figure 5). Degradation in non-cross-linked samples was characterized by a complete loss of weight. Cross-linking can increase scaffolds stability against the enzymatic degradation. This is due to the formation of a cross-link between the cross-linker and surface functional groups of scaffolds because of a dense network. The non-cross-linked samples exhibited a greater extent of enzyme degradation at each time point compared to those that were cross-linked. In addition, within a $72 \mathrm{~h}$ interval, noncross-linked samples were completely solubilized in enzyme solutions, while cross-linked samples were intact, especially those cross-linked mats containing CS. It is well-known that incorporation of GAG into $\mathrm{CO}$ indicates a significant increase of collagenase degradation resistance. ${ }^{49}$ Exposure of crosslinked CO-CS blend mats with collagenase exhibited more resistance to digestion compared to the $\mathrm{CO}$ samples only. 

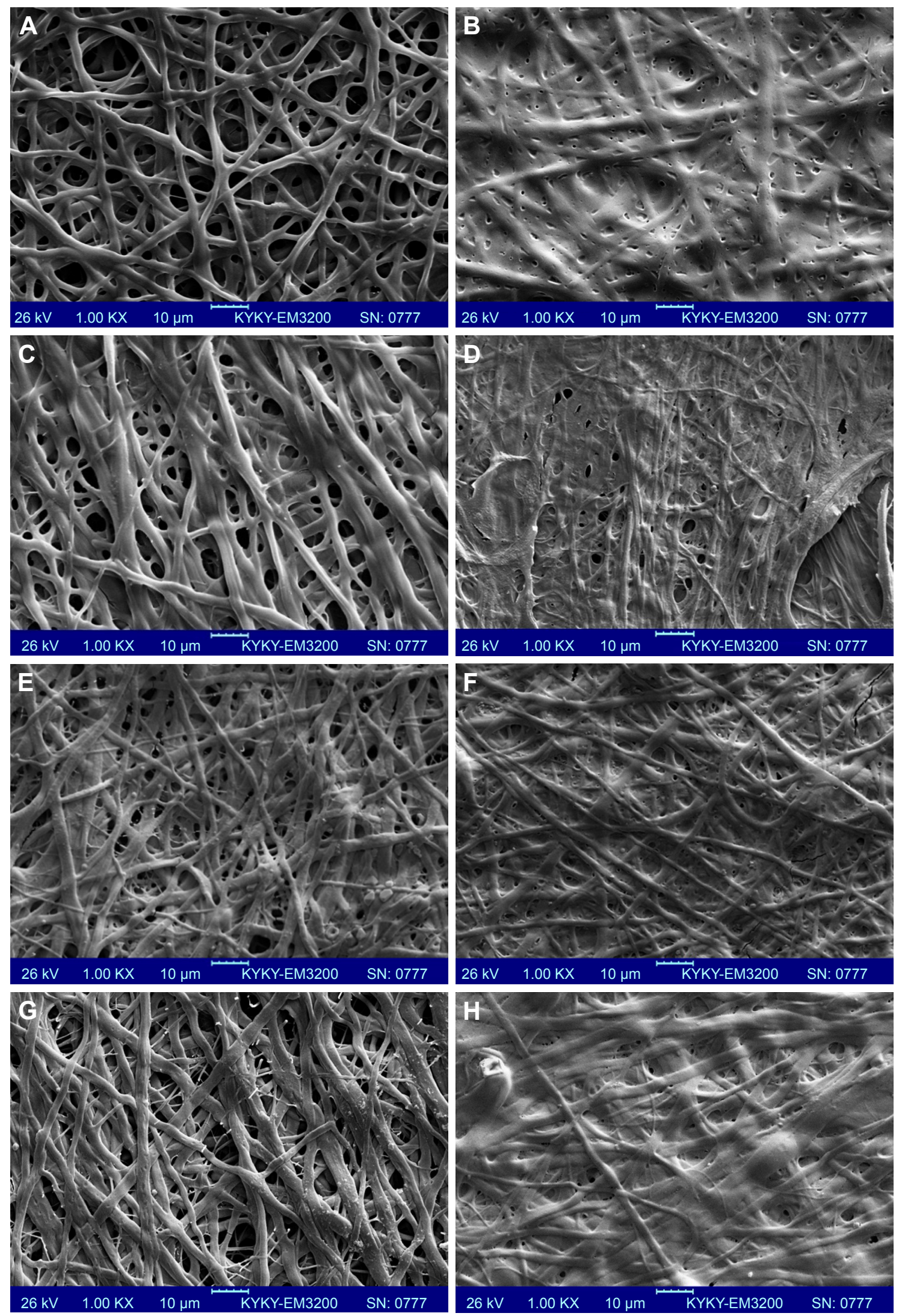

Figure 3 SEM images of the cross-linked nanofibrous mats with EDC cross-linker at different concentrations. Woven (A) $200 \mathrm{mM}$ and (B) $600 \mathrm{mM}$, and aligned CO (C) $200 \mathrm{mM}$ and (D) $600 \mathrm{mM}$ mats. Woven CO-CS (E) $200 \mathrm{mM}$ and (F) $600 \mathrm{mM}$, and aligned CO-CS (G) $200 \mathrm{mM}$ and (H) $600 \mathrm{mM})$ mats (I,000 $\times$ ).

Abbreviations: SEM, scanning electron microscopy; EDC, I-ethyl-3-(3-dimethyl-aminopropyl)-I-carbodiimide hydrochloride; CO, collagen; CS, chondroitin sulfate. 


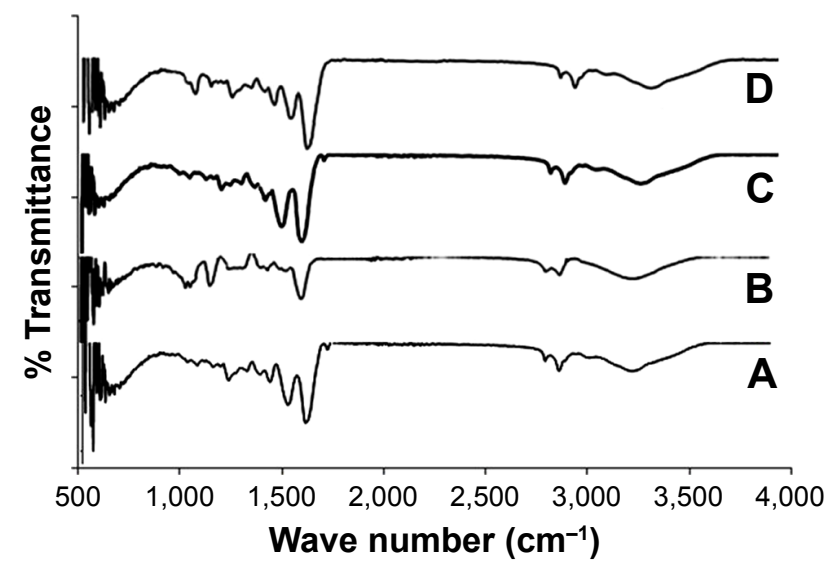

Figure 4 FTIR spectra for (A) CO, (B) CS, (C) cross-linked CO with EDC, and (D) CO-CS cross-linked with EDC.

Abbreviations: FTIR, Fourier-transform infrared spectroscopy; $\mathrm{CO}$, collagen; CS, chondroitin sulfate; EDC, I-ethyl-3-(3-dimethyl-aminopropyl)-I-carbodiimide hydrochloride.

The mats showed the least degradability due to the strong chemical cross-linking between $\mathrm{CO}$ and $\mathrm{CS}$.

SEM images have indicated an increasing fiber disintegration of collagenase digested samples as a function of time of exposure to the enzyme up to $24 \mathrm{~h}$. A complete degradation has been detected by enzyme after $4 \mathrm{~h}$ for $\mathrm{CO}$ and $\mathrm{CO}-\mathrm{CS}$ samples (Figure 6A). The diameter of the crosslinked electrospun fiber samples in collagenase decreased compared to the initial diameter after $24 \mathrm{~h}$ (Figure 6); while morphology of electrospun fibers have been accompanied only by a decrease in the size of the fiber diameter after $4 \mathrm{~h}$ of enzymatic incubation.
Figure 7 shows the mechanical properties of the nanofibrous mats. A higher tensile strength in the stress-strain curves can be seen in the mats with aligned morphology as compared with the woven ones. In addition, the $\mathrm{CO}$ mats containing CS showed higher tensile strength and a lower elongation percentage compared to electrospun mats before the treatment by cross-linker. This is compatible with the cross-linking CS, and $\mathrm{CO}$ was effective to increase the high mat mechanical integrity. The cross-linked $\mathrm{CO} / \mathrm{CS}$ mats significantly possess high tensile strength $0.55 \pm 0.05 \mathrm{MPa}$ for aligned and $0.46 \pm 0.01 \mathrm{MPa}$ for woven samples. However, the lower tensile strain at break or elongation is $\sim 18 \%$ for aligned and woven samples, compared to the noncross-linked one with a tensile strength of $0.14 \pm 0.1 \mathrm{MPa}$ for aligned and $0.12 \pm 0.2 \mathrm{MPa}$ for woven samples, and the elongation is $\sim 20 \%$ for non-cross-linked samples. Moreover, the cross-linked CO mats showed significantly higher tensile strength $(0.41 \pm 0.01 \mathrm{MPa}$ for aligned and $0.34 \pm 0.05 \mathrm{MPa}$ for normal samples) and lower elongation at $\sim 22 \%$. They are compared to the non-cross-linked ones (tensile strength of $0.25 \pm 0.3 \mathrm{MPa}$ for aligned and $0.21 \pm 0.5 \mathrm{MPa}$ for normal samples, and elongation of $\sim 30 \%$ ). Results of stress-strain curves demonstrated that the cross-linked $\mathrm{CO}$ and $\mathrm{CO}-\mathrm{CS}$ mats show good strength attributing to the role of crosslinking agent and GAG incorporation.

To determine the viability and proliferation of $\mathrm{HCE}$ cells on the non-cross-linked and cross-linked scaffolds, we measured cell proliferation ability over $72 \mathrm{~h}$ of incubation by MTT assay. Figure 8 presents the results determined by MTT

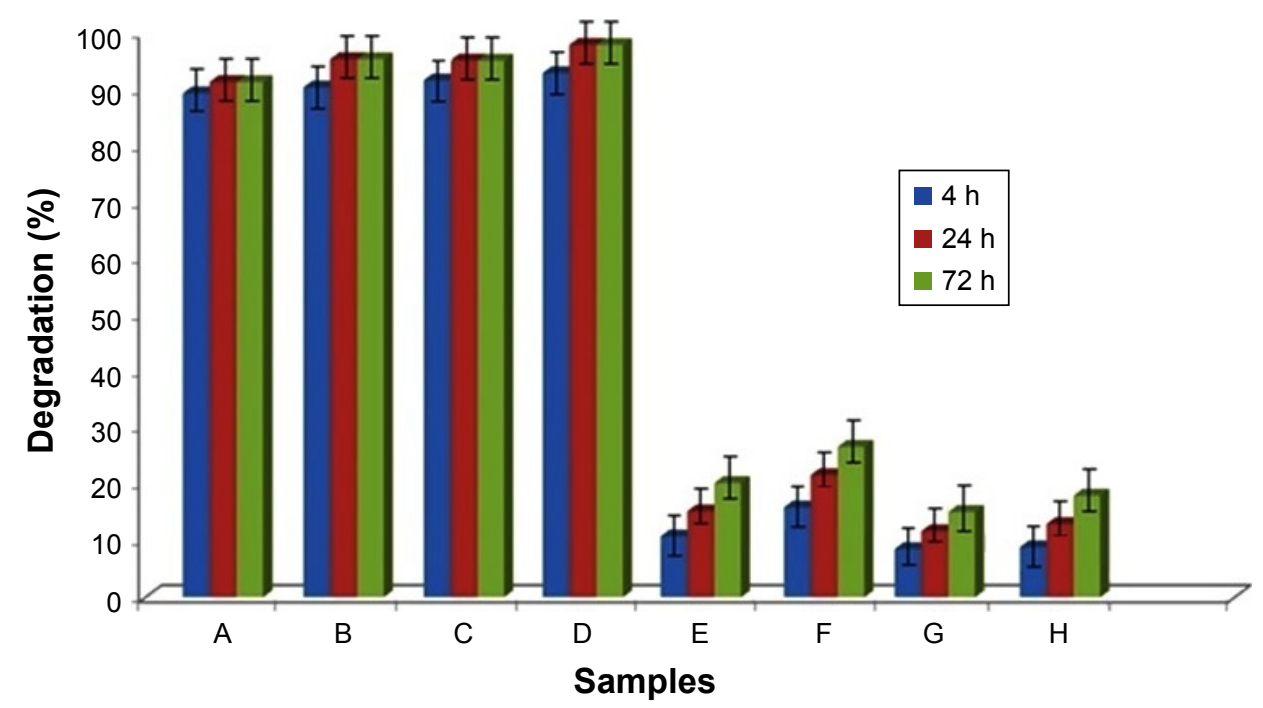

Figure $\mathbf{5}$ The degradation percent of cross-linked and non-cross-linked mats in collagenase solution at different times. Non-cross-linked (A) woven and (B) aligned CO, and non-cross-linked $(\mathbf{C})$ woven and $(\mathbf{D})$ aligned CO-CS mats, cross-linked $(\mathbf{E})$ woven and $(\mathbf{F})$ aligned CO, and cross-linked $(\mathbf{G})$ woven and $(\mathbf{H})$ aligned CO-CS mats $(P<0.05)$.

Abbreviations: $\mathrm{CO}$, collagen; $\mathrm{CS}$, chondroitin sulfate. 

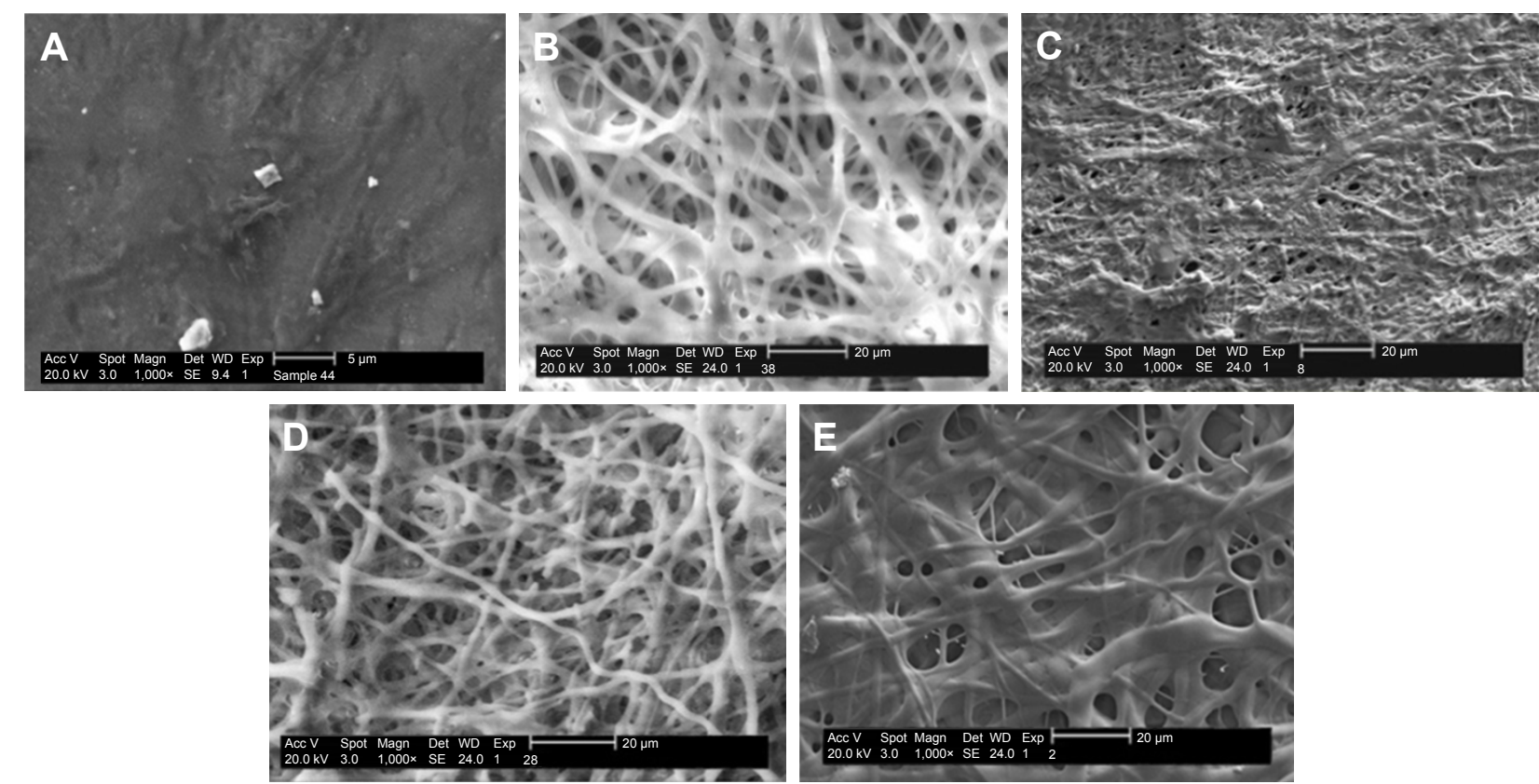

Figure 6 SEM images of degradability of the non-cross-liked and cross-linked electrospun mats. Non-cross-linked CO (A), cross-linked CO mats after 24 h (B) 200 mM EDC, and (C) 600 mM EDC, cross-linked CO-CS mats after 24 h (D) $200 \mathrm{mM} \mathrm{EDC}$ and (E) $600 \mathrm{mM}$ EDC (I,000x).

Abbreviations: SEM, scanning electron microscopy; CO, collagen; CS, chondroitin sulfate; EDC, I-ethyl-3-(3-dimethyl-aminopropyl)-I-carbodiimide hydrochloride.

as optical density for cross-linked samples in $200 \mathrm{mM}$ EDC after 4 and $24 \mathrm{~h}$. AM is used as control. The cross-linked mats showed lower viability compared to the non-cross-linked ones. The MTT assay showed that cell numbers could be increased by increasing the culture duration. As is shown in Figure 8, cell proliferation increased on all mats at day 3. This demonstrated that all nanofibrous mats possess adequate cytocompatibility for the growth of epithelial cells. On the other hand, a lower cell proliferation was observed in the cross-linked mats compared with the non-cross-linked mats. We have seen a similar growth pattern close to the control

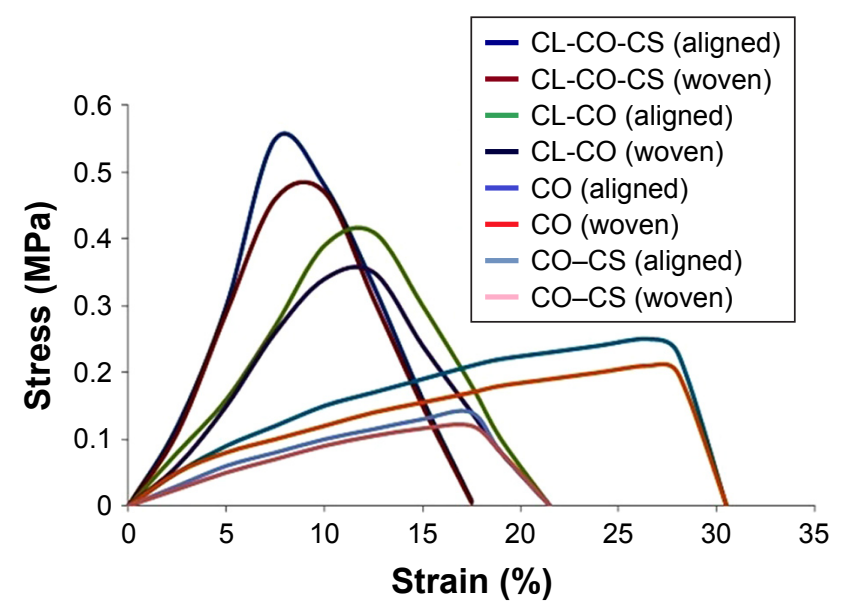

Figure 7 Stress-strain diagram of $C L$ and non-cross-linked nanofibrous mats of $C O$ and CO-CS $(P<0.05)$.

Abbreviations: $\mathrm{CL}$, cross-linked; $\mathrm{CO}$, collagen; $\mathrm{CS}$, chondroitin sulfate. for non-cross-linked mats, which clearly indicates that EDC chemical cross-linker decreased cell viability, and, in turn, induced toxicity, which finally could inhibit proper cell proliferation. The results carried out in studies earlier introduced CS as one of the most important GAGs, which induces the tissue regeneration like skin, ${ }^{50}$ and it enhances the osteoblast adhesion, and it conducts the mesenchymal stem cell differentiation to osteoblasts, ${ }^{51,52}$ as well as improved fibroblast proliferation by having fibroblast growth factor bonding sites. ${ }^{53,54}$ For the samples with CS, the incorporation of CS also significantly promoted the cell proliferation in comparison with the $\mathrm{CO}$ mats without $\mathrm{CS}$. For that reason, our results demonstrated the effect of addition of CS in stimulating cell proliferation and promoting cellular ingrowths.

SEM experiments were carried out to the cell attachment and morphology cultured over the CO-CS scaffolds after a 3-day cell culture. As is shown in Figure 9, HCE cells exhibited good attachment and spread on both the noncross-linked CO and CO-CS scaffolds. We observe voids in Figure 9A and $\mathrm{B}$ due to the degradation and breakage of the fibers during cell culture. This reflects the weak mechanical strength of the non-cross-linked mats upon biodegradation, while the intact structure was found on the cross-linked scaffold (Figure 9C-F). HCE cells showed a better proliferation and growth to form a compact layer on HAM as control (Figure 9G). The intact structure of CO, especially with 


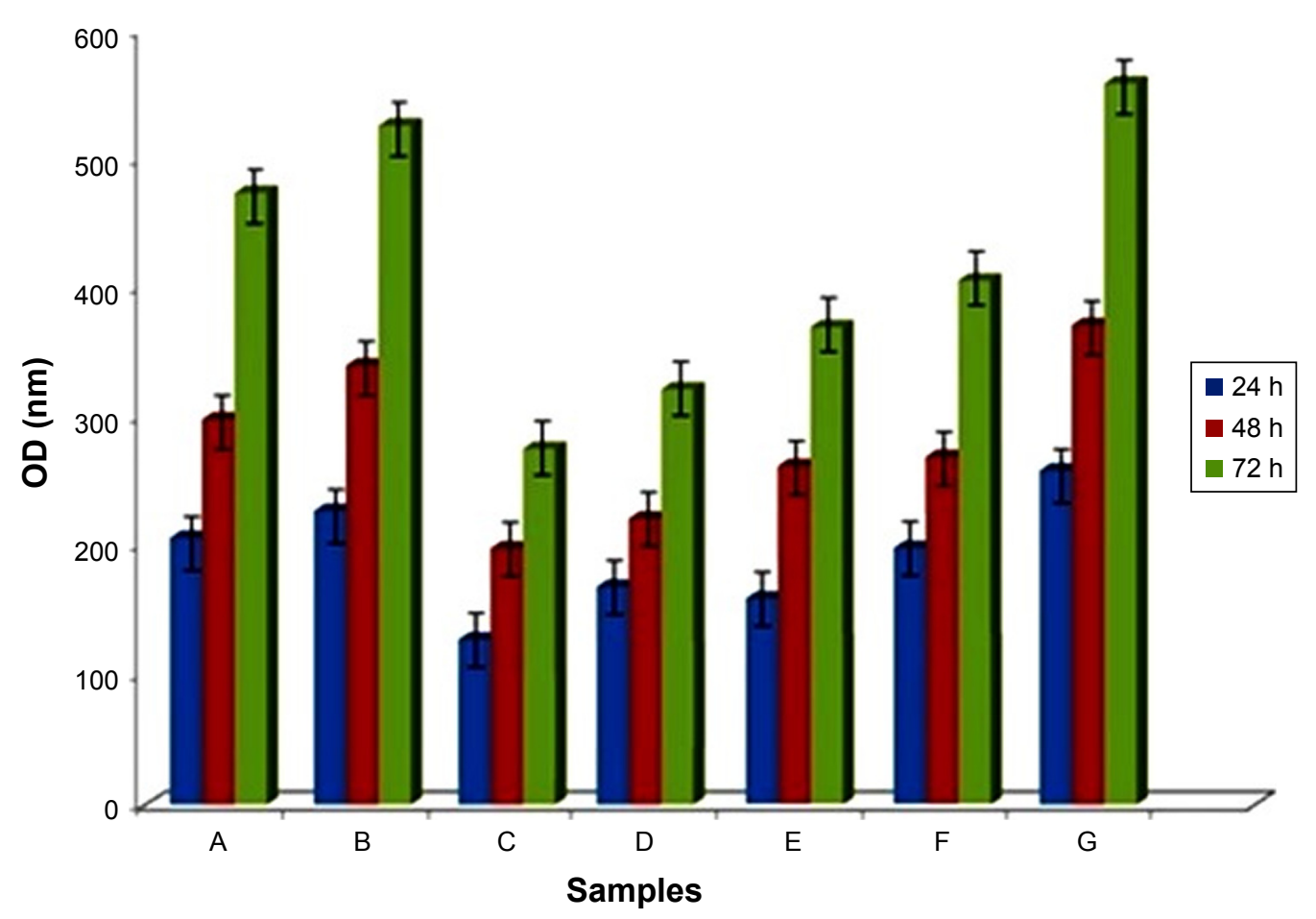

Figure 8 MTT assay of cultured HCE cells on non-cross-linked mats (A) CO and (B) CO-CS, cross-linked mats at $4 \mathrm{~h}$ (C) CO and (D) CO-CS, and cross-linked mats at $24 \mathrm{~h}(\mathbf{E}) \mathrm{CO}$ and $(\mathbf{F}) \mathrm{CO}-\mathrm{CS}$, Control (HAM) $(\mathbf{G})(P<0.05)$.

Abbreviations: MTT, 3-(4,5-dimethylazol-2-yl)-2,5-diphenyl-2H-tetrazolium bromide; HCE, human corneal epithelial; CO, collagen; CS, chondroitin sulfate; HAM, human amniotic membrane OD; OD, optical density.
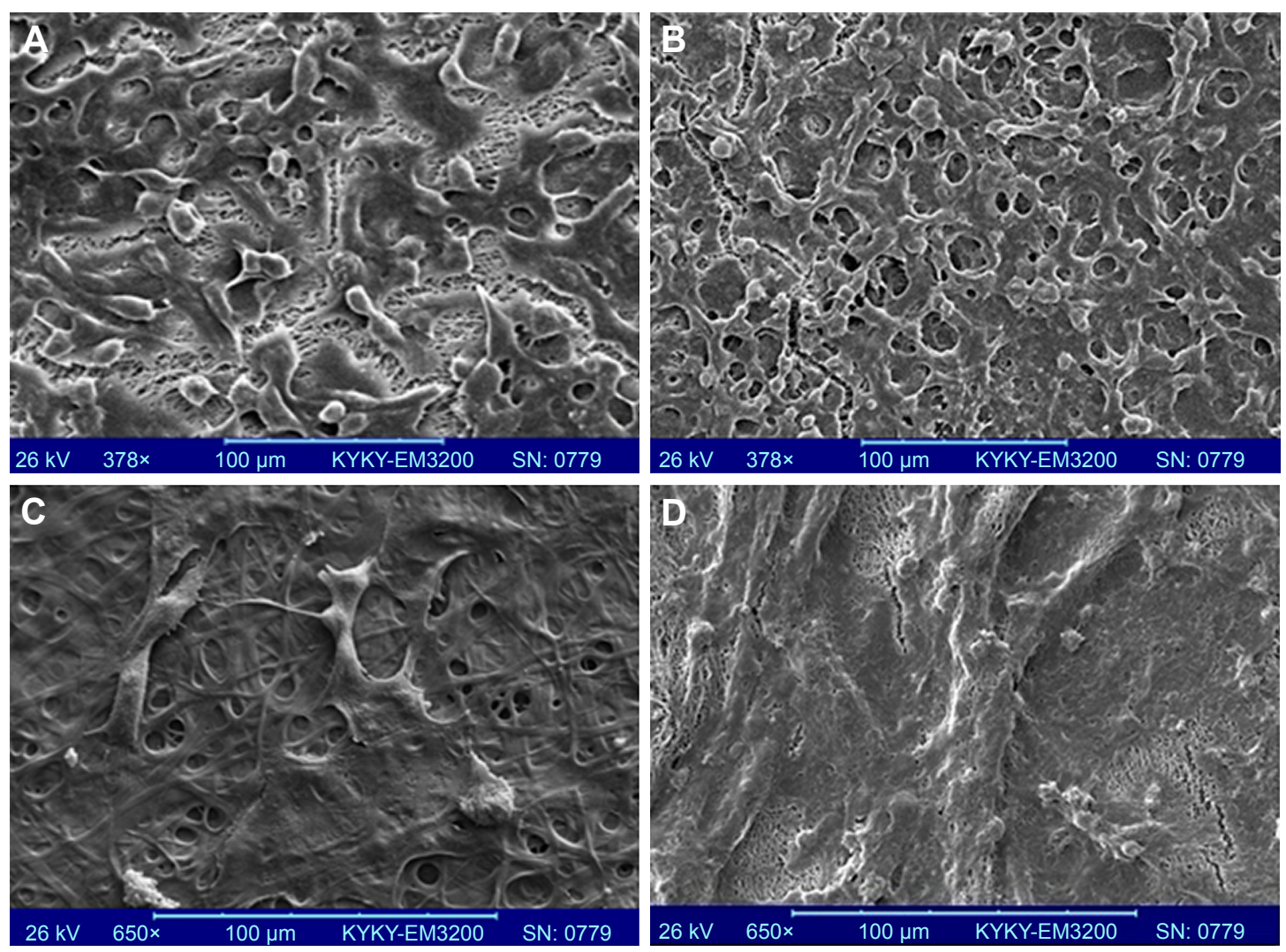

Figure 9 (Continued) 

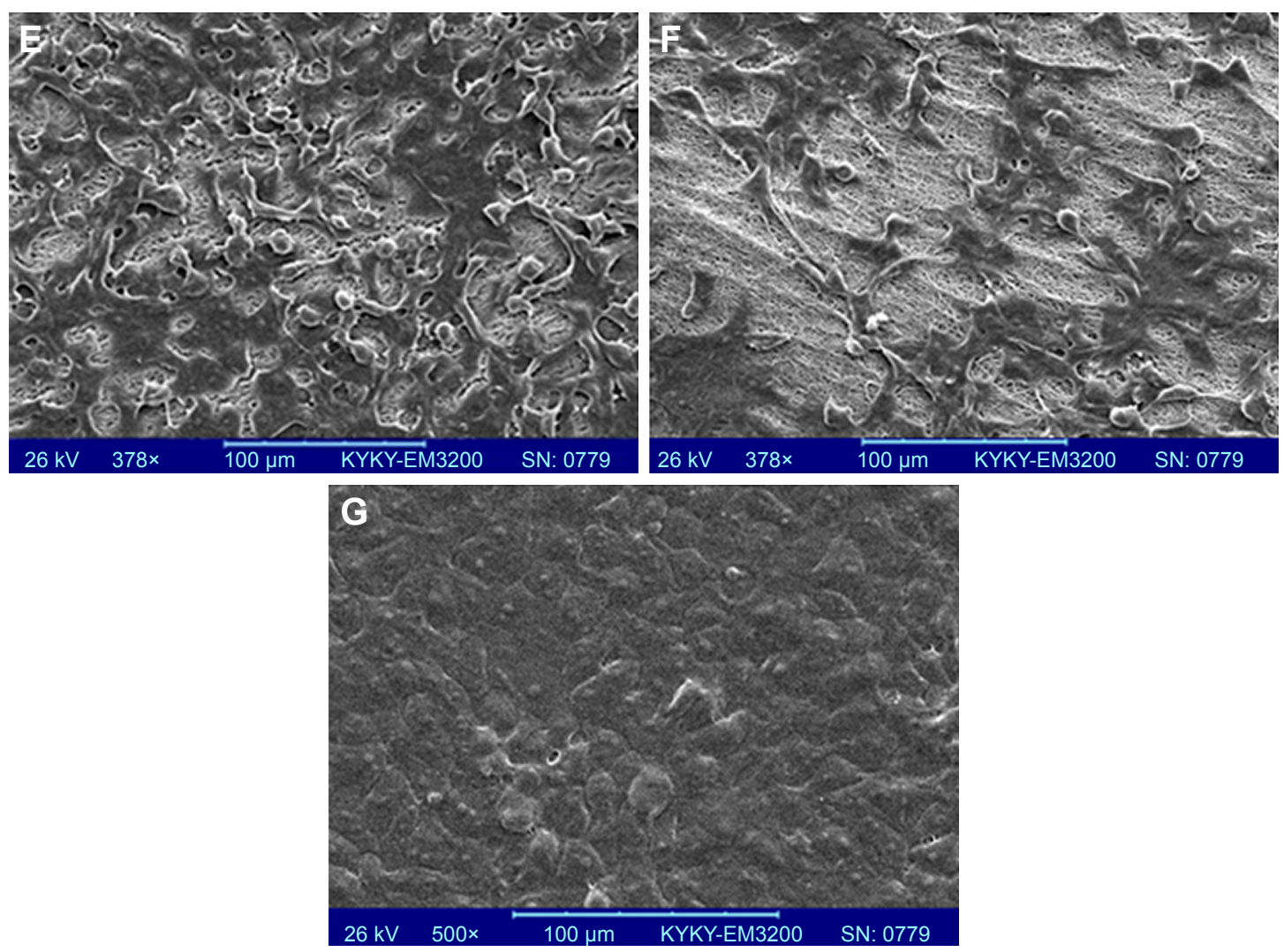

Figure 9 SEM images of the cultured cells on CO and CO-CS mats. Non-cross-linked mats (A) CO and (B) CO-CS, cross-linked CO (C) woven and (D) aligned, and cross-linked CO-CS (E) woven and (F) aligned mats, (G) Control (HAM).

Abbreviations: SEM, scanning electron microscopy; CO, collagen; CS, chondroitin sulfate; HAM, human amniotic membrane.

CS, indicates that cross-linking has succeeded in improving the biostability and cell adhesion as well as the mechanical strength of the mats. The high surface-to-volume ratio of nanofibers could enhance cell adhesion.

\section{Conclusion}

Woven and aligned nanofibrous $\mathrm{CO}-\mathrm{CS}$ scaffolds were designed by the electrospinning method, along with the cross-linked carbodiimide. The non-cross-linked and crosslinked electrospun mats exhibited a uniform nanofibrous and porous structure, especially for lower concentration of the cross-linker. The results which we obtained indicate that the scaffolds after cross-linking exhibited a high biostability from the $\mathrm{CO}$ digestion test. The suitable biocompatibility of cross-linked samples, which were treated to crosslinker at lower times with epithelial cells, was demonstrated by a standard cell proliferation assay. The potential of application of the CO-CS electrospun mats in tissue engineering is significant; because this scaffold made of natural ECM mimics the native ECM found in the soft tissues, it might eventually support more active tissue regeneration. These results show a promising lead that fabricated electrospun
CO-CS may be utilized as an alternative effective substrate in tissue engineering.

\section{Disclosure}

The authors report no conflicts of interest in this work.

\section{References}

1. Chan BP, Leong KW. Scaffolding in tissue engineering: general approaches and tissue-specific considerations. Eur Spine J. 2008;17: S467-S479.

2. Cen L, Liu W, Cui L, Zhang W, Cao Y. Collagen tissue engineering: development of novel biomaterials and applications. Pediatr Res. 2008;63(5):492-496.

3. Kadler KE, Holmes DF, Trotter JA, Chapman JA. Collagen fibril formation. Biochem J. 1996;316(1):1-11.

4. Lamond AI. Molecular biology of the cell, 4th edition. Nature. 2002; 417(6887):383.

5. Nayak R, Padhye R, Kyratzis IL, Truong YB, Arnold L. Recent advances in nanofibre fabrication techniques. Textile Res J. 2011;82(2): 129-147.

6. Ameri Bafghi R, Biazar E. Development of oriented nanofibrous silk guide for repair of nerve defects. Int J Polym Mater Polym Biomater. 2016; 65(2):91-95.

7. Biazar E, Baradaran-Rafii A, Heidari-keshel S, Tavakolifard S. Oriented nanofibrous silk as a natural scaffold for ocular epithelial regeneration. J Biomat Sci Polym Ed. 2015;26(16):1139-1151.

8. Sahebalzamani M, Biazar E, Shahrezaei M, Hosseinkazemi H, Rahiminavaie $\mathrm{H}$. Surface modification of PHBV nanofibrous mat by laminin protein and its cellular study. Int J Polym Mater Polym Biomater. 2015; 64(3):149-154. 
9. Sahebalzamani A, Biazar E. Modification of poly caprolactone nanofibrous mat by laminin protein and its cellular study. J Biomater Tissue Eng. 2014;4:423-429.

10. Momenzadeh D, Baradaran-Rafii A, Heidari Keshel S, Ebrahimi M, Biazar E. Electrospun mat with eyelid fat-derived stem cells as a scaffold for ocular epithelial regeneration. ArtifCells Nanomed Biotechnol. 2017; 45(1):120-127.

11. Majdi A, Biazar E, Heidari Keshel S. Fabrication and comparison of electro-spun poly hydroxy butyrate valrate nanofiber and normal film and its cellular study. Orient J Chem. 2011;27(2):523-528.

12. Baradaran-Rafii A, Biazar E, Heidari-Keshel S. Cellular response of limbal stem cells on PHBV/gelatin nanofibrous scaffold for ocular epithelial regeneration. Int J Polym Mater Polym Biomater. 2015;64: 879-887.

13. Baradaran-Rafii A, Biazar E, Heidari-Keshel S. Cellular response of stem cells on nanofibrous scaffold for ocular surface bioengineering ASAIO J. 2015;61(5):605-612.

14. Baradaran-Rafii A, Biazar E, Heidari-Keshel S. Cellular response of limbal stem cells on polycaprolactone nanofibrous scaffolds for ocular epithelial regeneration. Curr Eye Res. 2016;41(3):326-333.

15. Baradaran-Rafii A, Biazar E, Heidari-Keshel S. Cellular response of limbal stem cells on poly(hydroxybuthyrate-co-hydroxyvalerate) porous scaffolds for ocular surface bioengineering. Int J Polym Mater Polym Biomater. 2015;64:815-821.

16. Biazar E, Heidari Keshel S, Sahebalzamani A, Hamidi M, Ebrahimi M. The healing effect of unrestricted somatic stem cells loaded in nanofibrous polyhydroxybutyrate-co-hydroxyvalerate scaffold on fullthickness skin defects. J Biomater Tiss Eng. 2014;4:20-27.

17. Heidari Keshel S, Biazar E, Rezaei Tavirani M, et al. The healing effect of unrestricted somatic stem cells loaded in collagen-modified nanofibrous PHBV scaffold on full-thickness skin defects. Artif Cell Nanomed Biotechnol. 2014;42:210-216.

18. Biazar E, Heidari Keshel S. Effects of chitosan cross-linked nanofibrous PHBV scaffold combined with mesenchymal stem cells on healing of full-thickness skin defects. J Biomed Nanotechnol. 2013;9(9): 1471-1482.

19. Liu HF, Ding XL, Zhou G, Li P, Wei X, Fan YB. Electrospinning of nanofibers for tissue engineering applications. J Nanomater. 2013;1-11.

20. Frenot A, Chronakis IS. Polymer nanofibers assembled by electrospinning. Curr Opin Colloid Interf Sci. 2003;8:64-75.

21. Li WJ, Shanti RM, Tuan RS. Electrospinning technology for nanofibrous scaffolds in tissue engineering. Nanotechnol Life Sci. 2007;9 135-187.

22. Albu MG, Titorencu I, Ghica MV. Collagen-based drug delivery systems for tissue engineering. Biomater Appl Nanomed. 2011:333-358.

23. Dong B, Arnoult O, Smith ME, Wnek GE. Electrospinning of collagen nanofiber scaffolds from benign solvents. Macromol Rapid Commun. 2009;30:539-542.

24. Terada M, Izumi K, Ohnuki H, et al. Construction and characterization of a tissue-engineered oral mucosa equivalent based on a chitosan-fish scale collagen composite. J Biomed Mater Res B Appl Biomater. 2012; 100(7):1792-1802.

25. Bi M, Han H, Dong SH, et al. Collagen-coated poly(lactide-coglycolide)/hydroxyapatite scaffold incorporated with DGEA peptide for synergistic repair of skull defect. Polymers. 2018;10(2):109.

26. Wang J, Li D, Li T, et al. Gelatin tight-coated poly(lactide-co-glycolide) scaffold incorporating rhBMP-2 for bone tissue engineering. Materials. 2015;8(3):1009-1026.

27. Scott JE. Elasticity in extracellular matrix 'shape modules' of tendon, cartilage, etc. A sliding proteoglycan-filament model. J Physiol. 2003; 553(2):335-343

28. Frantz C, Stewart KM, Weaver VM. The extracellular matrix at a glance. $J$ Cell Sci. 2010;123(24):4195-4200.

29. Vrana NE, Builles N, Justin V, et al. Development of a reconstructed cornea from collagen-chondroitin sulfate foams and human cell cultures. Invest Ophthalmol Vis Sci. 2008;49(12):5325-5331.
30. Avram S, Shaposhnikov S, Buiu C, Mernea M. Chondroitin sulfate proteoglycans: structure-function relationship with implication in neural development and brain disorders. BioMed Res Int. 2014;2014;1-11.

31. Yannas IV, Lee E, Orgill DP, Skrabut EM, Murphy GF. Synthesis and characterization of a model extracellular-matrix that induces partial regeneration of adult mammalian skin. Proc Natl Acad Sci US A. 1989; 86(3):933-937.

32. Breinan HA, Minas T, Hsu HP, Nehrer S, Sledge CB, Spector M. Effect of cultured autologous chondrocytes on repair of chondral defects in a canine model. J Bone Joint Surg Am. 1997;79:1439-1451.

33. Hsu WC, Spilker MH, Yannas IV, Rubin PA. Inhibition of conjunctival scarring and contraction by a porous collagen-glycosaminoglycan implant. Invest Ophthalmol Vis Sci. 2000;41:2404-2411.

34. Zhong S, Teo WE, Zhu X, Beuerman R, Ramakrishna S, Yung LY. Formation of collagen-glycosaminoglycan blended nanofibrous scaffolds and their biological properties. Biomacromolecules. 2005;6: 2998-3004.

35. Wang S, Hu F, Li J, et al. Design of electrospun nanofibrous mats for osteogenic differentiation of mesenchymal stem cells. Nanomedicine. 2017;S1549-9634(17):30083-30087.

36. Luo XM, Fosmire GJ, Leach RM. Chicken keel cartilage as a source of chondroitin sulfate. Poult Sci. 2002;81:1086-1089.

37. Douglas T, Heinemann S, Mietrach C, et al. Interactions of collagen types I and II with chondroitin sulfates A-C and their effect on osteoblast adhesion. Biomacromolecules. 2007;8:1085-1092.

38. Myllyharju J, Kivirikko KI. Collagens, modifying enzymes and their mutations in humans, flies and worms. Trends Genet. 2004;20(1) 33-43.

39. Meng L, Arnoult O, Smith M, Wnek GE. Electrospinning of in situ crosslinked collagen nanofibers. J Mater Chem. 2012;22:19412-19417.

40. Torres-Giner S, Gimeno-Alcaniz JV, Ocio MJ, Lagaron JM. Comparative performance of electrospun collagen nanofibers cross-linked by means of different methods. Appl Mater Interfaces. 2009;1(1): 218-223.

41. Davidenko N, Schuster CF, Bax DV, et al. Control of crosslinking for tailoring collagen-based scaffolds stability and mechanics. Acta Biomater. 2015;25:131-142.

42. Sujithra S, Kiruthiga N, Prabhu MJ, Kumeresan R. Isolation and determination of type I collagen from Tilapia (Oreochromis niloticus) waste. IJET. 2013;5(3):2181-2185.

43. Koh LB, Islam MM, Mitra D, et al. Epoxy cross-linked collagen and collagen-laminin peptide hydrogels as corneal substitutes. J Funct Biomater. 2013;4:162-177.

44. Martínez A, Blanco MD, Davidenko N, Cameron RE. Tailoring chitosan/collagen scaffolds for tissue engineering: effect of composition and different crosslinking agents on scaffold properties. Carbohydr Polym. 2015;132:606-619.

45. Araki-Sasaki K, Ohashi Y, Sasabe T, et al. An SV40-immortalized human corneal epithelial cell line and its characterization. Invest Ophthalmol Vis Sci. 1995;36:614-621.

46. Qureshi IZ, Fareeha A, Khan WA. Technique for processing and preservation of human amniotic membrane for ocular surface reconstruction. Int J Biol Biomolec Agric Food Biotechnol Eng. 2010;4(9) 710-713.

47. Del Prado M, Lizárraga K, Giraldo D, et al. Development of collagenEDC scaffolds for skin tissue engineering: physicochemical and biological characterization. Int J Eng Res Sci. 2016;2(4):73-83.

48. Pek YS, Spector M, Yannas IV, Gibson LJ. Degradation of a collagenchondroitin-6-sulfate matrix by collagenase and by chondroitinase. Biomaterials. 2004;25:473-482.

49. Yannas IV, Burke JF, Huang C, Gordon PL. Suppression of in vivo degradability and of immunogenicity of collagen by reaction with glycosaminoglycans. Polymer Prepr Am Chem Soc. 1975;16:209-214.

50. Lee P, Tran K, Chang W, Shelke NB, Kumbar SG, Yu X. Influence of chondroitin sulfate and hyaluronic acid presence in nanofibers and its alignment on the bone marrow stromal cells: cartilage regeneration. J Biomed Nanotechnol. 2014;10:1469-1479. 
51. Bierbaum S, Douglas T, Hanke T, et al. Collageneous matrix coatings on titanium implants modified with decorin and chondroitin sulfate: characterization and influence on osteoblastic cells. J Biomed Mater Res A. 2006;77(3):551-562.

52. Wollenweber M, Domaschke H, Hanke T, et al. Mimicked bioartificial matrix containing chondroitin sulphate on a textile scaffold of poly(3hydroxybutyrate) alters the differentiation of adult human mesenchymal stem cells. Tissue Eng. 2006;12(2):345-359.
53. Asada M, Shinomiya M, Suzuki M, et al. Glycosaminoglycan affinity of the complete fibroblast growth factor family. Biochim Biophys Acta. 2009;1790:40-48.

54. Nandini CD, Mikami T, Ohta M, Itoh N, Akiyama-Nambu F, Sugahara K. Structural and functional characterization of oversulfated chondroitin sulfate/dermatan sulfate hybrid chains from the notochord of hagfish. Neuritogenic and binding activities for growth factors and neurotrophic factors. J Biol Chem. 2004;279(49):50799-50809.

\section{Publish your work in this journal}

The International Journal of Nanomedicine is an international, peerreviewed journal focusing on the application of nanotechnology in diagnostics, therapeutics, and drug delivery systems throughout the biomedical field. This journal is indexed on PubMed Central, MedLine, CAS, SciSearch ${ }^{\circledR}$, Current Contents ${ }^{\circledR} /$ Clinical Medicine,
Journal Citation Reports/Science Edition, EMBase, Scopus and the Elsevier Bibliographic databases. The manuscript management system is completely online and includes a very quick and fair peer-review system, which is all easy to use. Visit http://www.dovepress.com/ testimonials.php to read real quotes from published authors. 